\title{
Penile Bead Implantation in Relation to HIV Infection in Male Heroin Users in Taiwan
}

Tony Szu-Hsien Lee*

Department of Health Promotion and Health Education, National Taiwan Normal University, Taiwan

\begin{abstract}
Background: Recent reports indicate that injection risk behavior has declined among injection drug users (IDUs) but sexual risk behavior continues. RuJu, classified as a form of body modification, is the practice of permanently inserting beads beneath the foreskin of the penis. A man who has penis beads does not comfortably use a condom while having sex. This study examined the possible association of RuJu with human immunodeficiency virus (HIV) infection among IDUs in Taiwan.
\end{abstract}

Methods: Of 644 eligible male heroin users who agreed to participate in the study, 573 (89\%) completed consent forms and a questionnaire between June and August 2008. Clinical characteristics (HIV, hepatitis C, and RuJu) were retrieved from their medical files. Multinomial logistic regression was performed to examine the association of RuJu and HIV seropositivity, with drug risk behavior and sexual risk behavior controlled for.

Results: 206 respondents (36\%) were HIV positive, 428 (75\%) were HCV positive, and 232 (40\%) had RuJu beads. $21 \%$ reported condom use at last sex and $34 \%$ reported multiple sexual partners during the last 6 months. $88 \%$ reported that they had injected heroin within the last 6 months, $18 \%$ shared a needle at last injection, and $26 \%$ shared rinses at last injection. Multinomial logistic regression analysis revealed that HIV-positive IDUs were more likely than HIV-negative IDUs to have HIVIAIDS knowledge, to have had RuJu and an IDU partner, and to have used a condom at last sex and shared needles and rinse water at last heroin use.

Conclusion: Prevalence rates of HIV, HCV, and RuJu are high among IDUs seen at Taiwan drug detention centers. The results show that RuJu is highly associated with HIV seropositivity. Practitioners who seek to prevent HIV in male IDUs should be aware of the RuJu culture. More research on the role of RuJu in HIV infection is suggested.

Keywords: Condom use; Heroin abusers; HIV; Risk behavior; RuJu

\section{Introduction}

Injection Drug Users (IDUs) are at risk for overdose death [1] and psychiatric comorbidity [2]. They are especially at risk for infection by the Human Immunodeficiency Virus (HIV) and Hepatitis C Virus (HCV) through shared injection equipment and sexual intercourse $[3,4]$. Drug injections, HIV and HCV combined are very costly in terms of health care, crime and lost productivity [5]. UNODC (2011) [6] estimates that the overall number of drug users appears to have increased globally over the last decade, from 180 to about 210 million people (range: 149-272 million) and it is estimated that at least 60,000 people inject heroin in Taiwan [4]. Global estimates of the prevalence of HIV and HCV infection in IDUs in Asia have been high [3,4]. In Southeast Asia specifically, an estimated $16 \%$ to $58 \%$ of those who inject drugs have HIV [7]. Taiwan is no exception. For instance, in a study of 576 methadone maintenance treatment patients, it was found that $12 \%$ had HIV and 93\% had HCV [8]. Thus, IDUs are crucial for targeted $\mathrm{HIV} / \mathrm{HCV}$ prevention, methadone maintenance treatment and HIV treatment.

Behavior associated with HIV infection has received much empirical study. Results show that HIV can be transmitted by blood or other body fluids moving from an infected person to someone else. This IDU risk behavior can be drug-related (e.g., injecting drugs with shared equipment) or sex-related (e.g., consensual or nonconsensual intercourse without using a condom). Previous studies have documented that HIV risk behavior differs as a function of age, gender, education, ethnicity, employment status, poly drug use and duration of drug use [8,9-12].
The currently available clinical and behavioral interventions aimed at reducing HIV and HCV risk behavior are HIV counseling and testing, condom distribution, needle exchange programs and methadone maintenance treatment. A growing body of evidence from earlier intervention studies indicates that IDUs have reduced drugrelated risk behavior, such as needle and syringe exchange programmes [13] community outreach [14] and drug dependence treatment [15]. The incidence of HIV infection in IDUs fell during the past decade due to above mentioned programs in Southeast Asia [7] and Taiwan specifically [16].

Compared to significant decreases in injection risk behaviors, however, the percentage of using a condom during coitus remains low amongst IDUs. In Taiwan, studies have shown that a majority of IDUs with or without HIV have continued having sexual intercourse without condoms $[8,17,18]$ while 6 to 16 percent practiced sharing of needles or rinse water $[8,18]$. Additionally, the evidence about interventions to reduce sexual risk of IDUs has remained ambiguous [19]. For example,

${ }^{*}$ Corresponding author: Tony Szu-Hsien Lee, No 162 Sec. 1 He-Ping East Road Taipei, 10610, Taiwan, Department of Health Promotion and Health Education, National Taiwan Normal University, Taiwan, Tel: +886-2-7734-1701; E-mail: tonylee@ntnu.edu.tw

Received April 25, 2012; Accepted September 28, 2012; Published October 01, 2012

Citation: Lee TSH (2012) Penile Bead Implantation in Relation to HIV Infection in Male Heroin Users in Taiwan. J AIDS Clinic Res S1:018. doi:10.4172/2155-6113. S1-018

Copyright: (C) 2012 Lee TSH. This is an open-access article distributed under the terms of the Creative Commons Attribution License, which permits unrestricted use, distribution, and reproduction in any medium, provided the original author and source are credited. 
a study conducted on 154 IDUs [20] found that $29 \%$ continued risk sexual practices after knowing their HIV seropositivity and $58 \%$ of male IDUs did not use a condom during intercourse. A meta-analytic study [21] included 33 studies amongst IDUs between 1988 to 1999 with rigorous research designs and contained a sufficiently large enough sample found that the overall weighted average effect size for the 33 studies was significant but small.

The barriers to condom use during sexual intercourse amongst heroin users may go beyond the factors identified in the literature. For example, a study of 347 incarcerated IDUs in Bangkok, Thailand revealed that receiving tattoos in jail was associated with HIV infection [22]. In Southeast Asia, including mainland China and Taiwan there is a phenomenon of inserting self-made artificial nodules beneath the skin of the penis called RuJu, in which pearls, pieces of jade, or glass or metal beads are inserted [23]. Searched MEDLINE and reviewed 35 case reports and studies regarding penile bead implantation indicated that Ruju among male IDUs is especially prevalent in jails and prisoners often share their instruments using none or scarce disinfection [24]. Because the insertions are generally performed by the IDU or a fellow inmate, the insertion usually a leaves scar, indicating that the wound has not fully healed. In other words, RuJu may increase the risk of sexually transmitted diseases is that those who insert the beads (usually the IDUs themselves) do not know how to do so in a way that prevents medical complications [24]. These include reaction to a foreign body, oral and dental complications, aspiration and hypoxia, edema and swelling, streptococcal infections, and viral transmission including hepatitis and HIV. Thus, such failed "operations" are quite risky.

The hypothesis for this study was that $\mathrm{RuJu}$ is associated with condom use and HIV infection in addition to age, polydrug use, lack of knowledge about HIV transmission, and unsafe injection practices.

\section{Materials and Methods}

\section{Participants and design}

Participants for this cross-sectional study were recruited at three drug detention centers in Taiwan. Eligible participants were introduced to the purposes and procedures of the study by social workers at each prison. To recruit heroin users, a social worker from each detention center was approached and explained that this is a HIV-related survey study. Potential participants were explained by the social workers and then checked about the selection criteria being: age over 20, literate, a history of heroin offense during the past 6 months, sexually experienced, and no severe psychiatric symptoms. Participants were gathered in a classroom within a prison and the researcher debriefed this study and their confidentiality, as well as their decision of study participation. IDUs can refuse to join or fill in any questions at any time. Before the questionnaire was administered, written informed consent was obtained from the participants and had volunteered to participate. Given the sensitivity of the subject matter and the vulnerability of the study population, this study was reviewed and approved by the Human Subjects Institutional Review Board of Taipei Medical University. No incentive was rendered to the participants. The data were collected between June and August 2008.

\section{Measures}

The data consisted of responses to a structured questionnaire and the results of medical checkups. The questionnaire took about 15 minutes to complete. After the questionnaire responses and data from the medical files were merged, information that would reveal the participant's identify was erased.

\section{Clinical characteristics}

Before admission to a drug detention center, the Taiwan Ministry of Justice requires that drug offender's blood is drawn for serologic testing for HIV and HCV and the penis is checked for beads. In this study, participant records were retrieved from medical files stored on the drug detention centers' computer systems.

\section{Questionnaire}

The questionnaire included items on age, age at first drug use, age at first sex, age at first drug injection, and education in years. Other items concerned condom use at last sex, number of sexual partners during the last 6 months, heroin and amphetamine use in the last 6 months, and needle and rinse water sharing at last drug use (yes or no). Seven items assessed knowledge about AIDS and HIV transmission routes (sharing syringes, sharing rinse water, mosquito bites, sex without a condom, consistency of condom use, giving birth, and breast feeding). Possible scores ranged from 0 to 7.

\section{Statistical Analysis}

Analyses were conducted using SPSS version 16.0 [25]. Differences between the two HIV groups on items scaled categorically (demographic factors, clinical characteristics, and types of risk behavior) were evaluated by chi-square tests or Fisher exact tests if the cell sample was small. Continuous variables (age, age at first drug use, age at first sex, age at first injecting heroin, and HIV-related knowledge) were analyzed by independent-sample $t$ tests. Multinomial logistic regression was performed to examine associations between HIV infection and RuJu after controlling for demographics and drug-related and sex-related risks. Items with missing values were omitted from the analysis. The criterion for statistical significance was $\mathrm{p}<0.05$, two-tailed.

\section{Results}

\section{Demographics}

Of the 644 eligible participants, 573 (89\%) signed the consent forms and filled in the questionnaire. The average age was 35.82 years, education 9.62 years, age at first drug use 22.40 , age at first heroin injection 25.63, and age at first sex 16.84. Regarding clinical characteristics, $36 \%$ of the participants had HIV, $75 \%$ had HCV, and $40 \%$ had RuJu beads. The mean for knowledge about HIV transmission and AIDS risk behavior was 5.72 on the 7-point scale. As for sex-related practices, $21 \%$ used a condom at last sex, $22 \%$ had a sexual partner who was a heroin user, and 194 (34\%) reported multiple sexual partners during the last 6 months. As for drug-related practices, $45 \%$ used heroin and amphetamine during last 6 months; $88 \%$ reported heroin injection in the last 6 months; $18 \%$ shared needles and $26 \%$ shared rinse water at last heroin injection.

\section{Clinical characteristics and risk behavior}

Bivariate analyses revealed that knowledge about HIV/AIDS, polydrug use; $\mathrm{HCV}, \mathrm{RuJu}$, multiple sexual partners, injecting heroin, and sharing of needles and rinse water were all significantly associated with HIV status (Table 1). Specifically, HIV-positive IDUs scored higher than HIV-negative IDUs on knowledge about HIV/AIDS. Those who reported amphetamine and heroin use during the past 6 months were more likely than the other participants to be HIV-negative. Those who reported $\mathrm{RuJu}$ and multiple sexual partners were more likely to be HIV-positive. Those who reported injecting heroin and sharing needles and rinse water during the past 6 months were more likely to be HIVpositive than HIV-negative. 
Citation: Lee TSH (2012) Penile Bead Implantation in Relation to HIV Infection in Male Heroin Users in Taiwan. J AIDS Clinic Res S1:018. doi:10.4172/2155-6113.S1-018

Page 3 of 6

\begin{tabular}{|c|c|c|c|c|}
\hline & & HIV-positive & HI- negative & Total \\
\hline & & $n=206(36 \%)$ & $\mathrm{n}=367(64 \%)$ & $N=573(100 \%)$ \\
\hline Age & (years, mean \pm SD) & $35.00 \pm 7.78$ & $36.31 \pm 8.42$ & $35.82 \pm 8.21$ \\
\hline Education & (years, mean $\pm \mathrm{SD}$ ) & $9.34 \pm 2.36$ & $9.77 \pm 3.17$ & $9.62 \pm 2.91$ \\
\hline Age at first drug use & (years, mean $\pm S D$ ) & $21.86 \pm 6.84$ & $22.70 \pm 7.81$ & $22.40 \pm 7.48$ \\
\hline Age at first injecting heroin & (years, mean \pm SD) & $25.25 \pm 6.45$ & $25.85 \pm 6.44$ & $25.63 \pm 6.45$ \\
\hline Age at first sexual coitus & (years, mean $\pm S D$ ) & $16.65 \pm 3.34$ & $16.94 \pm 3.02$ & $16.84 \pm 3.14$ \\
\hline HIV transmission knowledge" & (range1-7,mean $\pm S D$ ) & $6.37 \pm 0.94$ & $5.58 \pm 1.24$ & $5.72 \pm 1.27$ \\
\hline Polydrug use in last 6 months" & Yes & $64(35 \%)$ & $178(51 \%)$ & $242(45 \%)$ \\
\hline$(n=534)^{a}$ & NO & $120(65 \%)$ & $172(49 \%)$ & $292(55 \%)$ \\
\hline \multirow[t]{2}{*}{$\mathrm{HCV}^{* *}(n=552)^{a}$} & Positive & $104(50.5 \%)$ & $41(11 \%)$ & $428(75 \%)$ \\
\hline & Negative & 102 (49.5\%) & $326(89 \%)$ & $145(25 \%)$ \\
\hline \multirow[t]{2}{*}{ RuJu“* (penis bead insertion) } & Yes & $111(54 \%)$ & $121(33 \%)$ & $232(40 \%)$ \\
\hline & No & $95(46 \%)$ & $246(67 \%)$ & $341(60 \%)$ \\
\hline \multirow[t]{2}{*}{ Used condom at last sex $(n=553)^{a}$} & Yes & $54(23 \%)$ & $72(20 \%)$ & $117(21 \%)$ \\
\hline & No & $150(77 \%)$ & $286(80 \%)$ & $436(79 \%)$ \\
\hline \multirow[t]{2}{*}{ Sexual partner used heroin" $(n=559)^{\text {a }}$} & Yes & $60(30 \%)$ & $63(18 \%)$ & $123(22 \%)$ \\
\hline & No & $138(70 \%)$ & $298(82 \%)$ & $436(78 \%)$ \\
\hline \multirow[t]{2}{*}{ Multiple sexual partners" } & Yes & $51(25 \%)$ & $143(39 \%)$ & 194(34\%) \\
\hline & No & $155(75 \%)$ & $224(61 \%)$ & $379(66 \%)$ \\
\hline \multirow[t]{2}{*}{ Injected heroin in last 6 months ${ }^{* *}$} & Yes & $203(99 \%)$ & $303(83 \%)$ & $506(88 \%)$ \\
\hline & No & $3(1 \%)$ & $64(17 \%)$ & $67(11 \%)$ \\
\hline \multirow[t]{2}{*}{ Shared needle at last injection" } & Yes & $61(30 \%)$ & $42(11 \%)$ & $103(18 \%)$ \\
\hline & No & $145(70 \%)$ & $325(89 \%)$ & $470(82 \%)$ \\
\hline Shared rinse water at last & Yes & $90(44 \%)$ & $57(16 \%)$ & $147(26 \%)$ \\
\hline injection" & No & $116(56 \%)$ & $310(84 \%)$ & $426(74 \%)$ \\
\hline
\end{tabular}

" $p<0.05 ;$; $p<0.01$; a Missing values were omitted from the statistical analyses;

Note: $x^{2}$ and t tests were used to examine differences between the HIV groups on categorical and continuous variables respectively. A Fisher exact test was performed to examine the relationship between HIV and heroin injection during the past 6 months

Table 1: Demographics, clinical characteristics and HIV risks as a function of the HIV status of male heroin abusers from drug detention centers

\begin{tabular}{|c|c|c|c|c|c|}
\hline \multirow[t]{2}{*}{ Variables } & \multirow[t]{2}{*}{ Estimates } & \multirow[t]{2}{*}{ SE of Estimates } & \multirow[t]{2}{*}{ OR } & \multicolumn{2}{|c|}{$95 \% \mathrm{Cl}$} \\
\hline & & & & Lower & Upper \\
\hline Age & 0.02 & 0.02 & 1.02 & 0.99 & 1.06 \\
\hline Education & 0.07 & 0.05 & 1.08 & 0.99 & 1.18 \\
\hline Knowledge about HIV infection ${ }^{*}$ & -0.72 & 0.12 & 0.49 & 0.38 & 0.62 \\
\hline Age at first drug use & 0.01 & 0.03 & 1.01 & 0.96 & 1.06 \\
\hline Age at first sex & -0.02 & 0.04 & 0.99 & 0.91 & 1.07 \\
\hline Hepatitis $C^{\star}$ & 2.59 & 0.30 & 12.54 & 7.03 & 22.35 \\
\hline Used condom at last sex ${ }^{*}$ & 0.78 & 0.33 & 2.18 & 1.15 & 4.15 \\
\hline Female drug use partner ${ }^{\star}$ & 0.59 & 0.30 & 1.81 & 1.01 & 3.24 \\
\hline Multiple sexual partners in last 6 months & -0.52 & 0.28 & 0.60 & 0.35 & 1.03 \\
\hline Polydrug use (heroin and amphetamines) ${ }^{*}$ & -0.59 & 0.28 & 0.55 & 0.32 & 0.96 \\
\hline Age at first heroin injection & -0.02 & 0.03 & 0.98 & 0.93 & 1.03 \\
\hline Shared needle at last heroin injection ${ }^{*}$ & 0.87 & 0.35 & 2.38 & 1.19 & 4.74 \\
\hline Shared rinse water at last heroin injection ${ }^{*}$ & 0.98 & 0.31 & 2.67 & 1.47 & 4.90 \\
\hline Penis beads ${ }^{*}$ & 0.91 & 0.29 & 2.47 & 1.40 & 4.36 \\
\hline
\end{tabular}

Note: $\mathrm{SE}=$ Standard Error; OR = Odds Ratio; $\mathrm{Cl}=$ confidence interval

Pseudo Nagelkerke $\mathrm{R}^{2}=0.58$

* $\mathrm{p}<0.05 ; * \mathrm{*}<0.01$.

Table 2: Multinomial Logistic Regression Analysis Associating HIV seropositivity with demographics, risk behavior and penis beads ( $\mathrm{n}=515$ )

\section{Factors associated with HIV seropositivity}

Results from the multinomial logistic regression analysis of HIV seropositivity as a function of demographics, clinical characteristics, and risk behavior are presented in table 2. HIV/AIDS knowledge scores were negatively related with HIV infection $(\mathrm{OR}=0.49,95 \%$ CI 0.38 , $0.62, \mathrm{p}<0.01)$. Participants with HCV were more likely than those without $\mathrm{HCV}$ to be HIV-positive ( $\mathrm{OR}=12.54,95 \%$ CI 7.03, 22.35, p $<0.05)$. Participants reporting condom use at last sex were less likely than others to be infected with HIV (OR $=2.18,95 \%$ CI $1.15,4.15, \mathrm{p}$ $<0.05)$. Participants who had a heroin-using partner were more likely than others to be HIV-positive ( $\mathrm{OR}=1.81,95 \% \mathrm{CI} 1.01,3.24)$, as were participants who shared needles and rinse water at last heroin injection $(\mathrm{OR}=2.38,95 \% \mathrm{CI} 1.19,4.74, \mathrm{p}<0.05 ; \mathrm{OR}=2.67,95 \% \mathrm{CI} 1.47,4.90, \mathrm{p}<$ 0.01 , respectively). Participants who had RuJu beads $(\mathrm{OR}=2.47,95 \% \mathrm{CI}$ $1.40,4.36, \mathrm{p}<0.01$ ) were more likely to be HIV positive. No significant associations were found for age, education, age at first drug use, age 
at first heroin injection, age at first sex, multiple sexual partners and polydrug use in the last 6 months.

\section{Discussion}

\section{$\mathrm{RuJu}$ as a risk for $\mathrm{HIV}$ infection}

A particularly noteworthy feature of the results is the high prevalence of $\mathrm{RuJu}(40 \%)$ among male IDUs in Taiwan. This finding is consistent with previous studies [23,24] which concluded the phenomenon of inserting artificial objects under the foreskin of the penis is most commonly observed among men from Southeast Asia and it is unusual in Western society. Data regarding the prevalence of penile beads implantation are few. A study [26] found that $51 \%$ of 100 young amphetamine users in Chiang Mai, Thailand had penile modification with the most common type inserting objects (61\%). Tsunenari et al. [27] found that in one Japanese prison $22 \%$ were nodule bearers among the Yakuza inmates.

The results of the present study also revealed a positive association between RuJu and HIV seropositivity after controlling for demographic characteristics, sex-related risk and drug-related risk behavior. One possible explanation is that having beads underneath the skin of the penis may dissuade IDUs from using condoms because the fixed beads would lead to painful intercourse and may cause abrasion of the genital organs of both men and women $[23,26]$. In addition, IDUs with RuJu had a higher risk of acquiring sexually transmitted diseases, including HIV by sharing instruments used for insertion and condom leakage [24]. A second reason why RuJu may increase the risk of HIV is that those who insert the beads may develop medical complications $[23,24]$. These include reaction to a viral transmission including hepatitis and HIV [28]. However, Marzouk [29] found that $96.6 \%$ of 60 interviewed beads bearers had suffered no complications in the 8 years after implantation. Also, the finding in this study indicated that IDUs with HIV self-reported high proportion of using a condom during the last sexual intercourse. It is a surprising finding and it is speculated that HIV positive IDU used a condom during sex after knowing their serostatus in order to stem the spread of HIV. Further research is needed to confirm such conflicting findings to disclose mechanism between RuJu, condom use, and infectious diseases.

\section{Prevalence of $\mathrm{HIV}$ and $\mathrm{HCV}$}

Because IDUs commonly share injection equipment (needles), and $\mathrm{HCV}$ and HIV are transmitted mainly through blood and serum, it is not surprising that we found high prevalence rates of HIV (36\%) and HCV (75\%) among our IDU participants. These results are consistent with previous studies $[3,28,30,31]$. The HIV prevalence rate we found is similar to that in other Southeast Asian countries [7]. Although it is difficult to compare our results to those from other studies with different recruitment strategies and settings, some patterns are noteworthy. The HIV prevalence rate in our study is higher than in previous Taiwan IDU studies. For example, in a study of IDUs recruited in Taiwanese methadone treatment clinics, the HIV prevalence rate was only $12 \%$, compared to our rate of $36 \%$ [8]. Another study conducted in correctional facilities [18] found that prevalence of HIV was $20 \%$ among heroin users. One possible explanation is that IDUs recruited from detention centers do not receive medical services that reduce HIV and HCV incidence. Another possibility is that IDUs with HIV are more likely to stay in the drug detention centers because, unlike prisons, such centers in Taiwan provide medical services and psychosocial therapy. As for $\mathrm{HCV}$ prevalence, previous studies have demonstrated that IDUs who administered drugs to themselves primarily by injection were more likely to have HCV than those who administered them in other ways (e.g., orally) $[3,32]$. These studies found high prevalence rates of HCV similar to what is found in this study. In most Asian countries, including Taiwan, drug users are tested for HCV but receive no treatment for it [33]. Hospitals should design and implement behavior counseling and education programs about HCV and general health, just as they do for HIV testing and counseling of men who have sex with other men. This recommendation is supported by evidence that HCV treatment can be successfully combined with methadone treatment [33].

\section{Risk behavior associated with HIV and HCV}

Our results consistently demonstrate that knowledge about HIV/ AIDS and drug-related and sex-related risk behavior are associated with HIV seropositivity. Previous studies have shown that many IDUs, after they learned they were HIV positive, paid increased attention to learning the routes of HIV transmission and what they could do to prevent others from becoming infected $[8,34]$. A study in Taiwan found that HIV incidence declined after extensive HIV/AIDS education in drug detention centers and prisons, even though the participants did not receive methadone maintenance treatment [16]. Given the demonstrated association between knowledge about HIV and HIV infection, education of IDUs about the transmission of HIV and HCV and the consequences of risky behavior must continue. Our result that sharing needles and rinse water is highly associated with HIV positivity is consistent with the literature on injection drug use. Recent reports have documented that HIV incidence and prevalence are declining among IDUs in Asia [7]. HIV education, methadone treatment and needle exchange programs targeting IDUs have been widely expanded in Taiwan. Consequently, the needle sharing rate at last injection in our study (18\%) is actually lower than in previous IDU studies in Taiwan (27\% to $29.6 \%$ ) [35,36]. Thus, prevention efforts focused on reducing injection risks among IDUs are the most likely cause of the decline in HIV.

The finding that no condom use at last sex was associated with HIV infection in our sample is consistent with previous studies of sexual risk behavior and HIV infection in IDUs $[9,17]$. One possibility is that behavioral interventions targeting IDUs emphasize the promotion of rational decision making and self-protective behavior. Proponents of this approach assume that individuals realize that certain activities are potentially harmful to their health and will change their behavior accordingly. However, one study found that male IDUs were unlikely to respond positively to calls for safer sexual practices, and that condom use rates can be as low as 4.3\% [37]. Declines have also been noted in unsafe sexual practices among IDUs, but they are not as dramatic as those found for injection risks.

Although condom availability, attitudes towards their use and trust relationships is important determinants of the frequency of condom use, the main focus in our study was RuJu. Three recommendations are suggested in this regard. First, RuJu should be included in the list of risky sexual practices in future risk behavior research. This research should be aimed at increasing our understanding of RuJu's role in the prevalence of condom use and HIV infection. Most Taiwanese IDUs have been incarcerated, and we found that a substantial number of our inmate participants had undergone a genital beads operation. In Taiwan, the purpose of the RuJu operation is to enhance sensuality during sexual intercourse. Only if questions are asked about why individuals choose $\mathrm{RuJu}$ can we increase our knowledge about the actual role of penis beads in coitus and in condom use. More research is also needed to determine the masculinity and sociocultural significance of RuJu and how this significance is related to condom use in this 
population. Second, IDUs with beads should be encouraged to have them removed. Education about the risks of RuJu and the infectious disease that can result therefrom must be initiated without delay. Third, more research is needed to examine how IDUs perceive sexual risk and HIV. Like tattooing, RuJu involves intimate parts of the body and thus has implications for how IDUs perceive their masculinity.

\section{Limitations of the study}

There are several limitations in this study. First, our original sample was limited to male IDUs in drug detention centers and $11 \%$ of these did not sign the consent form and complete the questionnaire. Thus, the study results may not be generalizable to community IDUs. Additionally, because we relied on self-reports of risk behavior, the results may be subject to reporting and recall biases. This limitation does not apply to the associations we found involving HIV, HCV, and $\mathrm{RuJu}$, because the data about these variables and other clinical characteristics were collected through medical examinations, which are more objective than self-reports.

\section{Conclusions}

This study has demonstrated high prevalence rates for HIV, HCV, and RuJu among IDUs in Taiwan. These results contribute significantly to the existing body of literature on vulnerable and high-risk IDUs. Previous studies examining sexual risk behavior in IDUs have focused on the consistency of condom use, multiple sexual partners, and exchanging sex for money or drugs. Despite the fact that condom use has been shown to be very low among male IDUs, their use has been reduced further by $\mathrm{RuJu}$ (the practice of inserting beads beneath the skin of penis) because the beads prevent condom use during sexual intercourse. RuJu is common and widely accepted in the Taiwanese population. Our results suggest that $\mathrm{RuJu}$ should be included in measures of sexual risk and addressed in HIV prevention. Moreover, the beads should be removed by hospital physicians, with the IDU's consent. More prospective studies are needed to understand the psychological factors that promote RuJu and to determine its specific effects on the acquisition and transmission of HIV and HCV.

\section{Acknowledgement}

This research was funded by National Science Council R.O.C. (Grants No. NSC95-2413-H-003-058- and NSC96-2314-B-003-003). We thank the participants for their time and effort.

\section{References}

1. Chen CY, Wu PN, Su LW, Chou YJ, Lin KM (2010) Three-year mortality and predictors after release: a longitudinal study of first-time drug offenders in Taiwan. Addiction 105: 920-927.

2. Chiang SC, Chan HY, Chang YY, Sun HJ, Chen WJ, et al. (2007) Psychiatric comorbidity and gender difference among treatment-seeking heroin abusers in Taiwan. Psychiatry Clin Neurosci 61: 105-111.

3. Aceijas C, Rhodes T (2007) Global estimates of prevalence of HCV infection among injecting drug users. Int J Drug Policy 18: 352-358.

4. Aceijas C, Stimson GV, Hickman M, Rhodes T (2004) Global overview of injecting drug use and HIV infection among injecting drug users. AIDS 18: 2295-2303.

5. Mark TL, Woody GE, Juday T, Kleber HD (2001) The economic costs of heroin addiction in the United States. Drug Alcohol Depend 61: 195-206.

6. United Nations Office on Drugs and Crime (2011) World drug report. New york.

7. UNAIDS (2011) UNAIDS report on the global AIDS epidemic 2010. New York.

8. Lee TSH, Shen HC, Wu WH, Huang CW, Yen MY, et al. (2011) Clinical characteristics and risk behavior as a function of HIV status among heroin users enrolled in methadone treatment in northern Taiwan. Subst Abuse Treat Prev Policy 6: 6.

9. Strathdee SA, Galai N, Safaiean M, Celentano DD, Vlahov D, et al. (2001) Sex differences in risk factors for HIV seroconversion among injection drug users: a 10-year perspective. Arch Intern Med 161: 1281-1288.

10. Hagan H, Thiede H, Weiss NS, Hopkins SG, Duchin JS, et al. (2001) Sharing of drug preparation equipment as a risk factor for hepatitis C. Am J Public Health 91: $42-46$.

11. Yang X, Latkin C, Celentano D, Luo H (2006) Prevalence and correlates of HIV risk behaviors among drug users in China. AIDS Behav 2: 71-81.

12. Koester S, Glanz J, Baron A (2005) Drug sharing among heroin networks: implications for HIV and hepatitis B and C prevention. AIDS Behav 9: 27-39.

13. Ksobiech K (2003) A meta-analysis of needle sharing, lending, and borrowing behaviors of needle exchange program attenders. AIDS Educ Prev 15: $257-$ 268.

14. Wiebel WW, Jimenez A, Johson W, Ouellet L, Jovanovic B, et al. (1996) Risk behavior and HIV seroincidence among out-of-treatment injection drug users: a four-year prospective study. J Acquir Immune Defic Syndr Hum Retrovirol 12: $282-289$.

15. Metzger DS, Woody GE, McLellan AT, O'Brien CP, Druley P, et al. (1993) Human immunodeficiency virus seroconversion among intravenous drug users in- and out-of-treatment: an 18-month prospective follow-up. J Acquir Immune Defic Syndr. 6: 1049-1056.

16. Lyu SY, Su LW, Chen YM (2012) Effects of education on harm-reduction programmes. Lancet 379: e28-30.

17. Lee TSH (2009) HIV susceptibility and risk behaviors amongst female heroin offenders in Taiwan. Formosan J Sexology 10: 53-64.

18. Lee TSH, Chen YP, Chang CW (2011) Gender differences in the perceived self-efficacy of safer HIV practices among polydrug abusers in Taiwan. Compr Psychiatry 52: 763-768.

19. Gibson DR, Flynn NM, Perales D (2001) Effectiveness of syringe exchange programs in reducing HIV risk behavior and HIV seroconversion among injecting drug users. AIDS 15: 1329-1341.

20. Singh BK, Koman JJ 3rd, Catan VM, Souply KL, Birkel RC, et al. (1993) Sexua risk behavior among injection drug-using human immunodeficiency virus positive clients. Intl J Addict 28: 735-47.

21. Des Jarlais DC, Semaan $S$ (2005) Interventions to reduce the sexual risk behavior of injecting drug users. Int J Drug Policy 16: 58-66.

22. Buavirat A, Page-Shafer K, van Griensven GJ, Mandel JS, Evans J, et al (2003) Risk of prevalent HIV infection associated with incarceration among injecting drug users in Bangkok, Thailand: case-control study. BMJ 326: 308.

23. Stankov O, Ivanovski O, Popov Z (2009) Artificial penile bodies-From Kama Sutra to modern times. J Sex Med 6: 1543-1548.

24. Fischer N, Hauser S, Brede O, Fisang C, Muller S (2010) Implantation of artificial penile nodules--A review of literature. J Sex Med 7: 3565-3571.

25. SPSS (2007) SPSS-16. Chicago, IL: SPSS, Inc.

26. Thomson N, Sutcliffe CG, Sirirojn B, Sintupat K, Aramrattana A, et al. (2008) Penile modification in young Thai men: risk environments, procedures and widespread implications for HIV and sexually transmitted infections. Sex Transm Infect 84:195-197.

27. Tsunenari S, Idaka T, Kanda M, Koga Y (1981) Self-mutilation. plastic spherules in penile skin in yakuza, Japan's racketeers. Am J Forensic Med Pathol 2: $203-$ 207.

28. Chitwood DD, Comerford M, Sanchez J (2003) Prevalence and risk factors for HIV among sniffers, short-term injectors, and long-term injectors of heroin. $J$ Psychoactive Drugs 35:445-453.

29. Marzouk E (1990) Implantation of beads into the penile skin and its complications. Scand J Urol Nephrol 24: 167-169.

30. Lee TSH (2010) A survey of HIV sero-prevalence and condom use among women who injected heroin. Taiwan J Public Health 29: 238-246.

31. Corsi KF, Lehman WK, Booth RE (2009) The effect of methadone maintenance on positive outcomes for opiate injection drug users. J Subs Abuse Treat 37 120-126. 
Citation: Lee TSH (2012) Penile Bead Implantation in Relation to HIV Infection in Male Heroin Users in Taiwan. J AIDS Clinic Res S1:018. doi:10.4172/2155-6113.S1-018

32. Mehta SH, Astemborski J, Kirk GD, Strathdee SA, Nelson KE, et al. (2011) Changes in blood-borne infection risk among injection drug users. J Infect Dis 203: 587-594.

33. Harris KA, Arnsten JH, Litwin AH (2010) Successful integration of hepatitis C evaluation and treatment services with methadone maintenance. J Addict Med 4: $20-26$

34. Weinhardt LS, Carey MP, Johnson BT, Bickham NL (1999) Effects of HIV counseling and testing on sexual risk behavior: a meta-analytic review of published research, 1985-1997. Am J Public Health 89: 1397-1405.
35. Chang CJ, Lin CH, Lee CT, Chang SJ, Ko YC, et al. (1999) Hepatitis C virus infection among short-term intravenous drug users in southern Taiwan. Eur $J$ Epidemiol 15: 597-601.

36. Lee TSH (2005) Prevalence and related factors of needle-sharing behavior among female prisoners. J Med Sci 25: 27-32.

37. Coulibaly S, Yen PMN, Fu LA, Chen YMA (2007) Needs assessment of people living with HIVIAIDS in Taiwan. Taiwan J Public Health 26: 38-48. 